\title{
TRANSPARENCY INDICATORS TO IMPROVE ACCOUNTABILITY FOR NON-PROFIT ORGANIZATIONS: A SPANISH CASE STUDY
}

\author{
Antonio Luis MORENO-ALBARRACÍN (D) 1, Cristina ORTEGA-RODRÍGUEZ (D)1, \\ Ana LICERÁN-GUTIÉRREZ (iD 1*, Álvaro LABELLA (D)2 , Luis MARTÍNEZ (D)2 \\ ${ }^{1}$ Department of Financial Economics and Accounting, University of Jaén, Jaén, Spain \\ ${ }^{2}$ Department of Computer Science, University of Jaén, Jaén, Spain
}

Received 07 October 2020; accepted 11 April 2021

\begin{abstract}
We are currently witnessing the development of a set of organizations that have been entrusted with meeting the very diverse needs of citizens. As a result, they receive funds, in order to ensure they are managed appropriately. The transparency of the information revealed by Non-profit Organizations (NPOs) has become of increasing interest to public authorities and research. However, very few studies empirically measure the extent of transparency in NPOs. Only a handful checked the compliance of various indicators, lacking agreement on which ones to include and their weighting. To address this issue, this study empirically validates the weighting of the indicators from the alliance between the Platform for Social Action NGO and the Spanish Coordinator for Development NGO (CONGDE) document with experts in NPOs' opinions. We use the Best-Worst Method (BWM) to optimally assign weights to multi-criteria decision making situations. Our results show interesting differences in the level of importance given to the indicators by public authorities and experts, suggesting the need for a revision of the importance proposed.
\end{abstract}

Keywords: transparency, batteries of indicators, non-profit organizations (NPOs), Best-Worst Method (BWM).

JEL Classification: M41, L31.

\section{Introduction}

In a world of growing social demands, the role of Non-profit Organizations (NPOs, hereafter) is crucial. This is recognized by both public authorities and the society in general.

NPOs are accomplishing functions intended to strengthen the achievement of the social and ecological dimensions of sustainable development (Valentinov \& Vaceková, 2015). For this purpose, peace is necessary, as is good governance of organizations. The present research is largely justified by the Sustainable Development Goals (SDGs) promulgated by the United

${ }^{\star}$ Corresponding author. E-mail: aliceran@ujaen.es

Copyright $\odot 2021$ The Author(s). Published by Vilnius Gediminas Technical University

This is an Open Access article distributed under the terms of the Creative Commons Attribution License (http://creativecommons. org/licenses/by/4.0/), which permits unrestricted use, distribution, and reproduction in any medium, provided the original author and source are credited. 
Nations. NPOs have become an essential element of the so-called social economy. Social economy entities are responsible for promoting social and economic transformations with a direct impact on the environment in which they operate. The Division for Sustainable Development Goals (DSDG) in the United Nations Department of Economic and Social Affairs (UNDESA) provides support and capacity-building for the SDGs and their related issues. SDGs comprise economic, social and environmental aspects (Anwar et al., 2020). DSDG plays a key role in the evaluation and implementation of the 2030 Agenda. The 2030 Agenda for Sustainable Development, contains 17 Sustainable Development Goals (SDGs). We have focused our study on the goals 16.6 Develop effective, accountable and transparent institutions at all levels and 17.19 (...) build on existing initiatives to develop measurements of progress on sustainable development that complement gross domestic product, and support statistical capacity-building in developing countries. Improving transparency and good governance in NPOs is a way of working towards a sustainable environment, ultimately trying to build a better world. The sustainability of the planet rests on many bases. According to the United Nations, Goal 16 Peace, Justice and Strong Institutions is achieved by reducing violence and abuse, but also by fostering effective and transparent accountable institutions at all levels.

To achieve all of the aforementioned goals, NPOs need to receive funds from public authorities and private donors. Consequently, these organizations make an effort to disclose information regarding the appropriate use of the funds received. Transparency of disclosed information in NPOs has become a hot topic in accounting literature. However, an analysis of prior literature on transparency in this sector has revealed a series of concerns.

Some examples of the aforementioned sets of indicators, particularly in Spain, are those proposed by the Platform for Social Action NGO and the Spanish Coordinator for Development NGO (CONGDE, hereafter), the Loyalty Foundation or the Commitment and Transparency Foundation. These set select a wide variety of indicators, and have a lack of consensus regarding which indicators better represent the concept of transparency in an empirical sense. Moreover, the only set that indicates weights for the indicators is from CONGDE (2019), and does not provide a theoretical foundation nor an empirical validation for such weights. As a theoretical contribution, our study highlights a gap in prior literature on information disclosure in the Non-profit Sector: the proposal of an appropriate selection of indicators that correctly measures the extent transparency of disclosed information by NPOs with an adequate weighting of the indicators according to their importance to explain transparency.

To fill this gap, we propose an optimal weighting of a set of indicators. The Best-Worst Method (BWM) optimizes the weighting of a series of indicators according to the relative importance of the different criteria when compared to the others, using experts (Rezaei, 2015). In our study, different experts representing the six most important social entities in Spain have answered a questionnaire using the BWM to compare the importance they give to the indicators proposed by CONGDE. To obtain a general and reliable weight for each indicator in agreeance with all of the experts' opinions in which they agree, a consensus reaching process (CRP) must be applied (Saint \& Lawson, 1994). In a CRP, experts discuss and modify their initial opinions in order to bring them closer together and achieve a consensual value that satisfies the majority of the group. In our proposal, we apply a CRP 
that allows a consensual weight to be computed for each indicator, in order to represent its importance regarding transparency.

A second contribution from an empirical point of view is, the proposed weighted set of indicators with the weighting from the CONGDE battery. Interestingly, our results show the discrepancy between the relative importance of the different indicators perceived by public authorities and by the experts, thereby suggesting the need for revision of the proposed weighting by public authorities. In this sense, our study could be helpful for practitioners, public regulators and supervisory authorities by serving as a guide to improve the assessment of the extent of NPO transparency and disclosure.

The aim of our study is to obtain a series of indicators to measure the extent of transparency of any NPO, proposing an optimal weight for each those transparency indicators according to their importance, which is empirically validated by experts in this sector, with a great extent of consensus on the weight of such indicators.

\section{Theoretical background. Measurement of transparency in the information disclosed by NPOs}

\subsection{Transparency in NPOs. Importance and challenges}

Nowadays, the recognition of the activity of NPOs in our society has increased due to the growth of complex social problems (Austin, 2000) and their response to such collective needs, improving the social and economic environment (Manville \& Greatbanks, 2016). This social role implies responsibilities from these organizations, existing a growing concern about promoting ethical attitudes to manage NPOs. Such concern has increased due to the inappropriate behaviour of some NPOs (Greenlee et al., 2007), damaging the traditional image of the credibility of this sector (Valencia et al., 2015).

One of the key aspects of credibility is the transparency of disclosed information to stakeholders (Sanzo-Pérez et al., 2017). However, there is no explicit, unique definition of the concept "transparency" in the literature. Clarifying this concept is one of the most complex and important issues facing the Non-profit Sector (Benjamin, 2008; Tacon et al., 2017). Transparency is related to the availability of information that improves the stakeholders' decision-making process, allowing them to evaluate and detect inefficiencies in the performance of NPOs (Sanzo-Pérez et al., 2017; Tremblay-Boire \& Prakash, 2015). Consequently, transparent disclosing by NPOs should provide their stakeholders relevant and reliable information (Burger \& Owens, 2010; Gandía, 2011) specially, to their donors (Keating \& Frumkin, 2003). This may enhance perceived trust of NPOs (Gandía, 2011) and ensure that the application of the received funds do not deviate from the social mission (Hale, 2013). A lack of transparency in this sector is worrisome (Burger \& Owens, 2010) due to the potential loss of support from donors, volunteers, resulting in the consequent organizational failure (Hale, 2013; Speckbacher, 2008).

Thus, there is a growing concern by managers of NPOs of the need to increase the transparency of disclosed information, given the public and social supervision of their fiscal, ethical, and performance accountability of the money they receive (Greenlee et al., 2007; Schatteman, 2013). However, the Non-profit Sector lacks of a clear and uniform regulation in 
this sense (Greenlee et al., 2007; Schatteman, 2013). This fact leads NPOs to adopt self-regulated actions, such as the voluntary disclosure of key organizational information (Hale, 2013).

In conclusion, recent studies highlight the increasing importance of transparent information in NPOs (Burger \& Owens, 2010; Hale, 2013; Sanzo-Pérez et al., 2017), although few empirical studies measure it. Considering the vast number of empirical studies, the number of papers that try to measure the extent of transparency in NPOs is scant (Ortega-Rodríguez et al., 2020). Moreover, these studies disagree on how to measure transparency, which suggest the need for a suitable transparency measurement technique.

\subsection{Measurement of the transparency of disclosed information in NPOs: The use of indicators}

Literature provides models to measure the performance of NPOs (Cestari et al., 2018; Willems et al., 2014) using indicators (Kim, 2017; Righi \& Andreoni, 2014). However, non-profit transparency measurement systems in particular have received limited attention.

One of the most common techniques to assess the extent of the transparency of NPOs is by checking whether NPOs meet several items (referred to as indicators) that are indicative of transparency (Valencia et al., 2015). Indicators are instruments that check the extent of compliance of several aspects of a given variable. In turn, those indicators may be used to make comparisons between different NPOs. Following the previous definition, we can point out some advantages of using indicators to measurement of transparency in NPOs: i) Indicators may improve the performance of NPOs and increase the transparency and the trust of funders and the society (Righi \& Andreoni, 2014). ii) From the CONGDE perspective (2019), indicators in NPOs guarantee an adequate level of transparency based on a responsible exercise of self-regulation. iii) It is an easy and inexpensive tool to apply (Righi \& Andreoni, 2014).

Notwithstanding, several problems arise when indicators are used as instruments to measure transparency. There is no a common agreement on which indicators should be considered neither what the importance of each indicator to represent transparency is. It would be necessary, thus, to establish a common framework of transparency indicators that could be adapted to each NPO. The data obtained by the indicators should be easily interpretable, enabling a comparison between different organizations of the non-profit sector.

In an attempt to propose a potential solution to this problem, we have considered the implementation of a set based on indicators. This model is expected to offer guidance to the NPO managers who wish to disclose useful and easily interpretable information about received funds management to their stakeholders. This, together with the accounting system should contribute to giving the organisation a good reputation.

\subsection{Transparency of NPOs in Spain}

The set of transparency indicators in the non-profit sector in the international setting and, more specifically, in the Spanish context, require a systematic contrast process.

Other sectors should be revised, e.g., there are set of indicators implemented in the public sector. In this sense, the work proposed by the Spanish organization Transparency International Spain stands out in this field. This organization has developed indicators to rank 
the transparency of municipalities, autonomous communities, councils, parliaments, public companies and political parties. This work has become a reference for the public authorities of Spain.

The aforementioned model could be adopted as a reference to work with a similar technique in the Non-profit Sector. However, the analysis should account for the specific characteristics of this sector such as the role of covering social needs, which is difficult to quantify (Franco \& Raja, 2014), or the fact that profit maximization is not the main target for the firm (Hofmann \& McSwain, 2013).

Different institutions have proposed a set of indicators that refer to qualitative and quantitative aspects of the transparency of the financial information that is disclosed by NPOs. In Spain, the main set of indicators proposals come from four entities: Loyalty Foundation, Commitment and Transparency Foundation, Spanish Association of Accounting and Business Administration (AECA) and CONGDE. However, a few problems arise. The indicators proposed by those entities are not homogeneous, they are not included in all of the set and their different weights differ depending on which institution proposes them (Moreno-Albarracín et al., 2020).

We have focused our study on the tool used by the CONGDE, as it is the most widely used and it comprises of more than 450 organizations. Moreover, the CONDGE is considered to be a representative authority in the Non-profit Sector in Spain that has made 11.400.000 attentions and had the collaboration of 5.011.000 members, 391.000 volunteers and 97.000 workers. Furthermore, this is the only set for which the careful consideration of the different indicators to measure transparency in NPOs is indicated (although these suggested weights are not empirically based nor theoretically explained). Considering the lack of theoretical and empirical evidence of the weights of the indicators in the CONGDE document, our study aims to provide an appropriate empirical assessment of the different indicators according to their importance in reflecting the transparency in a NPO.

\section{Methodology and research design}

\subsection{Methodology: Multi-criteria group decision making and the Best-Worst Method}

Multi-criteria group decision making (MCGDM) problems are characterized by a set of experts, $E=\left\{e_{1}, \ldots, e_{m}\right\}$, who evaluate different alternatives, $A=\left\{a_{1}, \ldots, a_{p}\right\}$, over a set of criteria, $C=\left\{c_{1}, \ldots, c_{n}\right\}$. For instance, a daily MCGDM problem in everyday life could be the purchase of a car, in which the alternatives might be different car models and the criteria might be features related to the cars such as speed, consumption or potency. One of the most relevant tasks when trying to solve any MCGDM problem and obtain reliable solutions is criteria weighting. For this reason, different MCGDM weighting techniques have been introduced in the specialized literature, several of them based on the experts' opinions elicited by pairwise comparisons (Rezaei, 2015; Saaty, 1989) and in the nonprofit field (See for example: Celik \& Gumus, 2018; Džunić et al., 2018). As stated before, the measurement of transparency in NPOs is a complicated issue and there is not an empirical process to set the weights for the 
transparency indicators. Therefore, a formalized process that allows the weights for such indicators to be obtained is necessary and applying a MCGDM technique might fill this gap.

The BWM (Rezaei, 2015) is a MCGDM method that computes the prioritization of different decision elements using pairwise comparisons. This technique consists of comparing only the best and the worst element of the decision making problem with the remaining elements. In this way, BWM reduces the number of comparisons needed to obtain the prioritization values of the elements and, consequently, reduces the inconsistency in decision makers' opinions represented by pairwise comparison matrices, which is provoked when the number of comparisons is too large.

Usually, BWM is used to obtain the weights for the criteria of a MCGDM problem. To do this, the best criterion $C_{B}$ and the worst criterion $C_{W}$ are selected by the decision makers and compared with the rest of the criteria. The following steps compromise the BWM for the criteria weights computation are (Rezaei, 2015):

1. First; determine a set of decision criteria.

2. Second; select the best criterion $C_{B}$ and the worst criterion $C_{W}$. If there are several best and/or worst criteria, they are selected randomly.

3. Third; make pairwise comparisons between $C_{B}$ and the rest of the criteria, by obtaining the Best to others (BO) vector, $B O=\left\{a_{B 1}, a_{B 2}, \ldots, a_{B n}\right\}$, where $a_{B j}$ represents the preference degree of $C_{B}$ over the criterion $C_{j}$ and $a_{B 1} \geq 1, j=1,2, \ldots, n, j \neq B$.

4. Fourth; make pairwise comparisons between $C_{W}$ and the rest of the criteria, by obtaining the Worst to others (WO) vector, $W O=\left\{a_{1 W}, a_{2 W}, \ldots, a_{n W}\right\}$, where $a_{j W}$ represents the preference degree of the criterion $C_{j}$ over $C_{W}$ and $a_{j W} \geq 1, j=1,2, \ldots, n, j \neq B$ or $W$.

5. Fifth; compute the criteria weights by using optimization models. For each reference comparison, the optimal criteria weights satisfy $w_{B} / w_{j}=a_{B j}$ and $w_{j} / w_{W}=a_{j W}$. Hence, the maximum absolute differences $\left|w_{B} / w_{j}-a_{B j}\right|$ and $\left|w_{j} / w_{W}-a_{j W}\right|$ should be minimized.

$$
\text { s.t }=\left\{\begin{array}{c}
\left|\frac{w_{B}}{w_{j}}-a_{B j}\right| \leq \varepsilon \\
\left|\frac{w_{j}}{w_{W}}-a_{j W}\right| \leq \varepsilon \\
\sum_{j=1}^{n} w_{j}=1 \\
w_{j} \geq 0 \forall j=1,2, \ldots, n
\end{array} .\right.
$$

A consistency ratio for evaluation was also introduced in the consistency of the decision makers' opinions (Rezaei, 2015). A comparison is fully consistent when $a_{B j} \times a_{j W}=a_{B W}, \forall j$, where $a_{B j}$ is the preference of the best criterion is over the criterion $j, a_{j W}$ is the preference of the criterion $j$ over the worst criterion and $a_{B W}$ is the preference of the best criterion over the worst criterion. The consistency ratio is computed as follows: 


$$
\text { Consistency Ratio }=\frac{\varepsilon^{*}}{\text { Consistency Index }},
$$

where $\varepsilon^{*}$ represents the maximum absolute difference among the optimal weights and the reference comparisons and Consistency Index is a numerical values obtained from $a_{B W}$ (Rezaei, 2015).

We consider BWM to be an appropriate technique in our field of research, given that it permits a reasonable assessments of NPO transparency criteria to be carried out based on expert opinions in NPOs.

\subsection{Methodology: Consensual weights for transparency indicators}

The BWM allows the weights to be obtained for the indicators from experts' opinions represented by pairwise comparison matrices. Such opinions, however might be conflictive. If we want to obtain a global weight for each specific indicator, in which the group agree, we should apply a CRP (Butler \& Rothstein, 2007; Saint \& Lawson, 1994).

A CRP is a dynamic and iterative process in which initial opinions are modified to bring experts' preferences closer in order to be able reach an agreed solution. Thus, once we have obtained a set of weights for the indicators from each expert, our aim is to apply a CRP to obtain a consensual weight for each indicator. There are multiple CRP proposals in the specialized literature (Ben-Arieh \& Easton, 2007; Labella et al., 2018; Rodríguez et al., 2018) but, for this contribution, we have used a minimum cost consensus (MCC) model (Ben-Arieh \& Easton, 2007), in an attempt to obtain a consensual solution by preserving the initial experts' opinions as much as possible. Therefore, for our problem, the weights of the indicators computed by using the BWM are modified until a consensus weight is reached, the MCC model guarantees that such consensual value is computed by changing the experts' opinions as little as possible. It is defined as:

$$
\begin{aligned}
& \min \sum_{k=1}^{m} c_{k}\left|\bar{o}_{k}-o_{k}\right|, \\
& \text { s.t. } \bar{o}_{k}-\bar{o} \leq \varepsilon, k=1,2, \ldots, m,
\end{aligned}
$$

where $o_{k}$ represents the weight obtained from the expert's opinion $e_{k}$ for a specific indicator, $\bar{o}_{k}$ represents the modified weight for such expert, $\bar{o}$ represents the collective opinion for the group and $\varepsilon$ measures the absolute deviation between each expert's modified opinion and the collective opinion.

\subsection{Research design}

\subsubsection{Variable definition: Description of the criterion to be weighted}

As previously mentioned, we will focus on a transparency analysis based on the indicators proposed by CONGDE. The purpose is to determine the appropriate weighting of both the criteria that are indicative of the extent of transparency (blocks of indicators) and the sub criteria that will be considered for each of these blocks. For a detailed definition of the variables, see Table 1. 
Table 1. Variable definitions

\begin{tabular}{|c|c|}
\hline $\begin{array}{c}\text { Blocks of } \\
\text { indicators }\end{array}$ & $\begin{array}{c}\text { Subcriteria } \\
\text { (Public availability of the following aspects) }\end{array}$ \\
\hline \multirow{5}{*}{$\begin{array}{l}\text { TR1 } \\
\text { Structure } \\
\text { and com- } \\
\text { position of } \\
\text { the Gov- } \\
\text { ernment } \\
\text { Board. }\end{array}$} & $\begin{array}{l}\text { TR1.1: Composition of the Government Board, including the name, responsibility in } \\
\text { the entity and description of their career path. }\end{array}$ \\
\hline & $\begin{array}{l}\text { TR1.2: Link between the members of the Government Board with liability charges } \\
\text { in the same institution (political party, trade union, holding, religious formation or } \\
\text { public administration), whenever the proportion of these charges exceed } 40 \% \text { of the } \\
\text { composition of the Government Board. }\end{array}$ \\
\hline & $\begin{array}{l}\text { TR1.3: Organization chart as well as the names of the main responsible members of } \\
\text { the executive structure. }\end{array}$ \\
\hline & TR1.4: Statutes and other specific rules. \\
\hline & TR1.5: Salary tables. \\
\hline \multirow{5}{*}{$\begin{array}{l}\text { TR2 } \\
\text { Defini- } \\
\text { tion of its } \\
\text { mission, } \\
\text { vision and } \\
\text { values. }\end{array}$} & TR2.1: Definition of the Mission of the entity. \\
\hline & TR2.2: Definition of the Vision of the entity. \\
\hline & TR2.3: List of Values of the entity. \\
\hline & $\begin{array}{l}\text { TR2.4: Information about the history of the events relative to the entity (constitution } \\
\text { year, motivation, founders and milestones). }\end{array}$ \\
\hline & $\begin{array}{l}\text { TR2.5: Ethical Recommendations for the Third Sector of Social Action and/or other } \\
\text { codes of conduct (specifically written or subscribed) of the entity. }\end{array}$ \\
\hline \multirow[t]{7}{*}{$\begin{array}{l}\text { TR3 } \\
\text { Social } \\
\text { Support. }\end{array}$} & $\begin{array}{l}\text { TR3.1: Quantitative data about the stakeholders (natural or legal persons) that conform } \\
\text { the social support of the entity (partners, donors, volunteers and beneficiary persons), } \\
\text { offering details about what to understand for each of these people. }\end{array}$ \\
\hline & TR3.2: Quantitative data about the employees of the entity. \\
\hline & TR3.3: List of the networks or federations to which the entity belong. \\
\hline & TR3.4: List of the public and private funders that are legal persons. \\
\hline & $\begin{array}{l}\text { TR3.5: Document that develops the criteria to ask for information and communicate } \\
\text { complains about the operating organizational structure (at least by e-mail or } \\
\text { telephone). }\end{array}$ \\
\hline & TR3.6: Information about the implementation of territorial organization (headquarters). \\
\hline & $\begin{array}{l}\text { TR3.7: Public aid and public and private subsidies that the entity receive (amount, } \\
\text { purpose and beneficiary groups). }\end{array}$ \\
\hline \multirow{10}{*}{$\begin{array}{l}\text { TR4 } \\
\text { Structure } \\
\text { and com- } \\
\text { position } \\
\text { of their } \\
\text { budgeting } \\
\text { process } \\
\text { and activi- } \\
\text { ties, and } \\
\text { their eco- } \\
\text { nomic and } \\
\text { financial } \\
\text { structure. }\end{array}$} & TR4.1: Strategic planning. \\
\hline & TR4.2: Private availability of the strategic planning. \\
\hline & $\begin{array}{l}\text { TR4.3: Annual financial statements of the entity (balance sheet, profit and loss } \\
\text { statement, budget document and economic memory). }\end{array}$ \\
\hline & TR4.4: Memory of the social activities of the entity on an annual basis. \\
\hline & TR4.5: Social records of the entity from previous three years. \\
\hline & TR4.6: Financial statements of the entity from the past three years. \\
\hline & $\begin{array}{l}\text { TR4.7: Report of the origin and application of the funds received by the entity to the } \\
\text { Third Sector Platform. }\end{array}$ \\
\hline & $\begin{array}{l}\text { TR4.8: Information in the social records of at least, the following aspects relative to the } \\
\text { programs and projects of the entity: title, region of development, amount of money } \\
\text { involved, collaborations or local partnerships, number of beneficiary people and } \\
\text { number of volunteers. }\end{array}$ \\
\hline & $\begin{array}{l}\text { TR4.9: Compliance of communication with people and institutions that give the } \\
\text { society finalist contributions (information about the activity that has been supported as } \\
\text { well as the main outcomes obtained from it). }\end{array}$ \\
\hline & TR4.10: Financial investments of the entity. \\
\hline
\end{tabular}




\subsubsection{Sample description}

To evaluate the weights of the relative importance of the different indicators and the blocks of indicators, we use primary data obtained from a questionnaire for experts people from a list of NPOs in the area of economic information (the questionnaire is available at https:// sinbad2.ujaen.es/sites/default/files/2020-04/Questionnaire.pdf). In further detail, the questionnaire was answered by the Accounting managers of six different NPOs that operate in Spain and that stand out for their vast experience in the Nonprofit Sector, and who are also in charge of the development of different sets of indicators, thereby evidencing a clear implication on the transparency of the information that is revealed to their stakeholders. Furthermore, the six chosen NPOs cover a wide variety of social needs.

\subsubsection{Phases for the empirical analysis}

Following the BWM steps defined in Section 2.1:

1. First; establish the group of decision criteria: The decision criteria are represented by the block of indicators that were defined in Section 2.3.1.

2. Second; determine the best $C_{B}$ and worst $C_{W}$ indicators. Then, design the questionnaire to be answered by the six experts. First, the interviewed experts should fill in a gap to indicate the block of indicators that they consider to be the most important (Question 1 from each block of questions) and the least important (Question 3 from each block) in order to be able to consider a NPO being transparent. Next, for each of these blocks of indicators there is a list of questions in which the interviewee is asked to reflect the most and least important indicator for each block of indicators.

3. Third; determination of the preference of the best indicator regarding the remaining indicators. To obtain the necessary data for this phase, Question 2 is included in each block of questions. To elaborate, Question 2 shows a table in which the person being interviewed compares the relative importance of the indicator that was selected as the best indicator in Question 1 with the remaining indicators. The relative importance is established according to a Likert scale, ranking from 1 (few important) to 5 (absolutely important). This generates the vector $B O^{k}=\left\{a_{B 1}^{k}, a_{B 2}^{k}, \ldots, a_{B n}^{k}\right\}$ for each expert $e_{k}$.

4. Fourth; The preference of all indicators from the worst criterion is determined. Just as it was in step 3, Question 4 is included so the person being interviewed is asked to compare the relative importance of the remaining indicators with respect to the worst indicator selected in question 3. From this process, we obtain the vector $W O^{k}=\left\{a_{1 W}^{k}, a_{2 W}^{k}, \ldots, a_{n W}^{k}\right\}$.

5. Fifth; Determine the optimal weights for each expert $e_{k},\left(w_{1}^{k}, w_{2}^{k}, \ldots, w_{n}^{k}\right)$. The weights of the indicators for each expert are computed using Eq. (1) (see Tables 2-6).

6. Sixth; determine of the consensual weights $\left(w_{1}, w_{2}, \ldots, w_{n}\right)$. A consensual weight for each indicator is computed using the MCC model (see Tables 2-6).

Note that, to calculate the optimal weights we have used the software tool FLINTSTONES developed by Estrella et al. (2014). 


\section{Discussion of the results}

In this section we present the results for the optimal weighting obtained. For a better understanding of the implications, we will present and discuss these results in different subsections. First of all, the general transparency results for the blocks of indicators are presented in Table 2. Next, Tables 3 to 6 show the results for the indicators of each general aspects (indicators for each block).

With the aim of comparing the BWM optimal consensus weights regarding the weighting in the set of indicators by CONGDE, we present both the weights in BWM for each of the participants.

\subsection{Results from the general aspects that are indicative of transparency}

As shown in the variables definition in Appendix 1, there are four aspects to evaluate: structure of the Government Board of the entity (Block 1); characteristics of the definition of its mision and vision, as well as the values that the company define as being essential (block 2); social suport (Block 3); and budgeting and presentation of results to the supervisory authorities (Block 4).

Regarding the general aspects, the set of indicators proposed by CONGDE does not offer any weighting on the importance of the aforementioned transparency aspects, but a ponderation of the indicators that are indicative of any of these general aspects. Hence, we can only show the results of the BWM (see Table 2), offering a general vision of the facts that experts consider to be more representative of transparency in NPOs.

According to Table 2, two of the aspects are considered to be more representative of transparency as compared with the other two aspects. Firstly, it is worth noting the great importance of the need to appropriately budget and disclose economic information to the stakeholders, and also to meet the expectations of the public authorities that supervise such economic information (TR4). Moreover, with the exception of an individual respondant which considers the aspect to have a lower weight (institution 2 , weight $=0.105$ ), the remaining institutions give this general aspect more a third of the weight, thereby confirming the superiority of this aspect as compared to the others. In general, the consensus value indicates that the importance of this aspect is over half that of the four aspects (consensus weight value: 0.517 ).

Table 2. Transparency-indicator weighting. General aspects (blocks of indicators)

\begin{tabular}{|l|c|c|c|c|}
\hline & TR1 & TR2 & TR3 & TR4 \\
\hline Institution_1 & 0.092 & 0.171 & 0.171 & 0.566 \\
\hline Institution_2 & 0.081 & 0.733 & 0.081 & 0.105 \\
\hline Institution_3 & 0.078 & 0.107 & 0.137 & 0.677 \\
\hline Institution_4 & 0.313 & 0.313 & 0.063 & 0.313 \\
\hline Institution_5 & 0.050 & 0.114 & 0.147 & 0.689 \\
\hline Institution_6 & 0.065 & 0.390 & 0.091 & 0.455 \\
\hline Consensus value & 0.104 & 0.252 & 0.127 & 0.517 \\
\hline
\end{tabular}


The second most important aspect is the appropriate definition of the mision, vision and values of NPOs (TR2). The mean value (0.252) reflects that the fourth part of perceived transparency relies on this aspect. However, in this case there is less agreement within the experts, because the value here is a considerably higher than the rest (institution 2 , for which the weight is 0.733 , while for the rest of the values it ranges from, approximaltely, 0.1 to 0.4 ). For the remaining institutions, this area is also considered to be the second most important inreflecting transparency.

Finally, we must note the lack of importance given to the Government Board (TR1) and Social Support (TR3) aspects in terms of transparency, with each two only slightly exceeding $10 \%$ of the weight (consensus weights values: 0.104 and 0.127 , respectively).

\subsection{Results for the Government Board indicators}

We present the results from each block of indicators in Table 3. Following the CONGDE order, we have started with the issues related to the Government Board of institutions.

As the CONGDE offers a possible weighting for each block of indicators, we will compare these orientative weights with the weights that have been validated with the BWM considering the experts' opinions.

A comparison between the BWM and CONGDE values shows a noteworthy overvaluation of the availability of the composition of the Government Board (TR1.1).CONGDE considers that this is the most important aspect (weight: 0.3 ), while the experts offer a considerably lower consensus value for the valuation of this aspect (consensus weight value: 0.175). Moreover, in the CONGDE set of indicators, this indicator is reinforced with the categorization of "inexcusable compliance". This difference leads us to think that a revision of this indicator would be advisable, due to the fact that because expert opinions indicate that this aspect may not be relevant.

On the other hand, while the experts considered, the availability of the organization chart and the composition of the executive board members (TR1.3) to be the second best indicator, it was suprisingly considered to be less important by the public authorities (weight of CONGDE: 0.1). Moreover, the extent of compliance suggested by CONGDE is also lower, they only considered it to be "relevant", rather than a criteria of inexcusable-compliance.

Table 3. Transparency-indicator weighting. Government board block

\begin{tabular}{|l|c|c|c|c|c|}
\hline & TR1.1 & TR1.2 & TR1.3 & TR1.4 & TR1.5 \\
\hline Institution_1 & 0.287 & 0.287 & 0.078 & 0.061 & 0.287 \\
\hline Institution_2 & 0.042 & 0.024 & 0.203 & 0.381 & 0.350 \\
\hline Institution_3 & 0.302 & 0.070 & 0.098 & 0.492 & 0.037 \\
\hline Institution_4 & 0.224 & 0.104 & 0.313 & 0.313 & 0.045 \\
\hline Institution_5 & 0.123 & 0.123 & 0.123 & 0.574 & 0.058 \\
\hline Institution_6 & 0.037 & 0.101 & 0.344 & 0.418 & 0.101 \\
\hline Set of indicators & 0.3 & 0.2 & 0.1 & 0.3 & 0.1 \\
\hline Consensus value & 0.175 & 0.113 & 0.186 & 0.405 & 0.122 \\
\hline
\end{tabular}


For the most important aspect, however, there is a general agreement of both the public authorities (weight of CONGDE: 0.3) and the experts (consensual weight value: 0.405 ). Such agreement of the experts in the most important indicator for an appropriate Government Board in a NPO is the public availability of the social statutes empirically confirms the intuitive greater extent of compliance given by public authorities to this aspect, considered as an inexcusable-compliance issue.

\subsection{Results for the indicators defined bymision, vision and values}

The second aspect that the CONGDE propose to represent transparency is an appropriate definiton of the mision, vision and values of a NPO. Moreover, as we indicated before, this is the second most important area according to the experts, highly-weighted. As such, it is essential that the weight of the different aspects indicative of this general aspect that are given by public authorities is empirically contrasted with the weights proposed by the experts. Table 4 shows the results from the BWM for the weighting of the indicators defined by this block, as well as those proposed by CONGDE.

And so, we find more similarities in the weighting proposed by CONGDE and the weighting extracted from the BWM experts analysis. This fact is reflected in a weight nearly equal for the indicators of the public availability of both the mision (TR2.1), vision (TR2.2) and ethical recommendations for the Non-profit Sector or other behavioral codes (TR2.5) as aspects to consider a higher extent of transparency. Regarding the strength of the extent of compliance, the empirical analysis validates the proposed consideration of public availabilty of the mision of a NPO as the most important aspect, which must be inexclusably complied.

Regarding the other two indicators, there is a greater disagreement between experts and public authorities. The public availability of the values of the entity (TR2.3) is overweighted by public authorities (CONGDE weight $=0.25$ vs. consensus weight value $=0.185$ ). On the other hand, experts consider the public availability of the historical evolution of the social entity (TR2.4) to be more important, with a similar importance perhaps similar to that of the etichal recommendations.

Table 4. Transparency-indicator weighting. Mission, vision and values block

\begin{tabular}{|l|c|c|c|c|c|}
\hline & TR2.1 & TR2.2 & TR2.3 & TR2.4 & TR2.5 \\
\hline Institution_1 & 0.200 & 0.200 & 0.200 & 0.200 & 0.200 \\
\hline Institution_2 & 0.339 & 0.028 & 0.059 & 0.395 & 0.178 \\
\hline Institution_3 & 0.335 & 0.074 & 0.437 & 0.103 & 0.051 \\
\hline Institution_4 & 0.532 & 0.106 & 0.106 & 0.106 & 0.149 \\
\hline Institution_5 & 0.175 & 0.555 & 0.097 & 0.047 & 0.125 \\
\hline Institution_6 & 0.214 & 0.250 & 0.250 & 0.036 & 0.250 \\
\hline Set of indicators & 0.3 & 0.2 & 0.25 & 0.1 & 0.15 \\
\hline Consensus value & 0.296 & 0.198 & 0.185 & 0.139 & 0.182 \\
\hline
\end{tabular}




\subsection{Results for the social support indicators}

As in the previous subsections, Table 5 shows the weights of the experts according to the BWM for the different transpreny indicators related to the issues of the social support of NPOs in relation to the proposed CONGDE indicator weighting.

Table 5. Transparency-indicator weighting. Social support block

\begin{tabular}{|l|c|c|c|c|c|c|c|}
\hline & TR3.1 & TR3.2 & TR3.3 & TR3.4 & TR3.5 & TR3.6 & TR3.7 \\
\hline Institution_1 & 0.208 & 0.276 & 0.034 & 0.208 & 0.105 & 0.063 & 0.105 \\
\hline Institution_2 & 0.054 & 0.032 & 0.204 & 0.054 & 0.204 & 0.075 & 0.376 \\
\hline Institution_3 & 0.299 & 0.046 & 0.391 & 0.066 & 0.066 & 0.066 & 0.066 \\
\hline Institution_4 & 0.083 & 0.083 & 0.083 & 0.303 & 0.064 & 0.083 & 0.303 \\
\hline Institution_5 & 0.040 & 0.040 & 0.280 & 0.040 & 0.280 & 0.280 & 0.040 \\
\hline Institution_6 & 0.071 & 0.036 & 0.250 & 0.071 & 0.286 & 0.143 & 0.143 \\
\hline Set of indicators & 0.25 & 0.15 & 0.15 & 0.1 & 0.15 & 0.1 & 0.1 \\
\hline Consensus value & 0.127 & 0.093 & 0.222 & 0.115 & 0.168 & 0.116 & 0.160 \\
\hline
\end{tabular}

According to the experts, this block of indicators is underestimated. Moreover, this block has the greatest number of indicators for which the values proposed by public authorities differs more in magnitude with the experts' opinions.

Firstly, the indicator for which public authorities give a higher extent of importance (weight CONGDE $=0.25$ ) and compliance (inexcusable compliance) is the existence of quantitative data and description of the different social supporters of the entitty (members, donnors, etc.) (TR3.1). However, experts do not consider this fact so important (consensus weight value $=0.127$ ). This result suggests the need to revise the importance given to this indicator by public authorities and perhaps even to revise, the possibility of reducing the extent of compliance to be able to consider a NPO as being transparent. In this sense, the indicator that the experts consider to be most important, based on consensus (consensus value weight $=0.222$ ), is the public availability of a list indicating the network or federations to which the NPO belongs (TR3.3). This indicator is given a lower weight (weight CONGDE = 0.15 ) and compliance rate (arelevant factor, not an inexcusable-compliance aspect) by public authorities, as opposed to other aspects such as the existence of a list of public and private funders that are legal persons (TR3.4)I (inexcusable-compliance strength). This is an apsect in which both CONGDE and experts agree, as they both give it less importance (weight CONGDE $=0.1$; consensus weight value $=0.115$ ).

Secondly, the indicator of the public availability of a list of the aids and subsidies that NPOs receive (TR3.7) is considered to be of inexcusable compliance by public authorities. However, in our opinion, the weight that is given by CONGDE for this indicator (0.1) is not representative of its perceived importance given by the experts (consensus weight value = 0.16). This greater allotment of importance could appear to be more logical according to the greater extent of compliance established by public authorities, which is the second most important indicator according to the experts. In conclusion, the extent of compliance is logical but it should be weighted as more important according to public authorities. 
Lastly, the existence of the quantitative data of NPO employees (TR3.2) is overweighted by public authorities (weight CONGDE $=0.15$ ) in comparison with the experts, who reduce the importance up to about half (consensus weight value $=0.093$ ) the value for this indicator. Summing up, public authorities are overvaluating aspects that are related to the quantiative data of the social entitites (TR3.1 and TR3.2) wherereas the experts consider the quantitative data to be less importante. Thus, there is an opportunity here for public authorities to reconsider their position and focus on other aspects that are more closely related to the funding of a NPO itself (TR3.3 and TR3.7).

\subsection{Results for budgeting and economic information disclosure indicators}

Once again, a block of indicators of a general aspect which is considered really important by experts to reflect transparency, as it is the budgeting process and the disclosing of econimic information relative to the NPO to public authorities, is a block with scant differences between the opinion of the experts and the one that is proposed by public authorities. A detailed comparison is shown in Table 6.

Most of the indicators reflecting a higher extent of transparency in terms of the economic information disclosed by the NPO show similar weights between experts' opinions and those proposed by CONGDE. However, we will comment on the discrepancies of only three of the ten indicators in this block.

Table 6. Transparency-indicator weighting. Budgeting and economic information disclosure block

\begin{tabular}{|l|c|c|c|c|c|}
\hline & TR4.1 & TR4.2 & TR4.3 & TR4.4 & TR4.5 \\
\hline Institution_1 & 0.080 & 0.031 & 0.166 & 0.166 & 0.048 \\
\hline Institution_2 & 0.035 & 0.202 & 0.035 & 0.046 & 0.269 \\
\hline Institution_3 & 0.097 & 0.039 & 0.340 & 0.054 & 0.069 \\
\hline Institution_4 & 0.201 & 0.061 & 0.201 & 0.061 & 0.061 \\
\hline Institution_5 & 0.066 & 0.066 & 0.318 & 0.085 & 0.085 \\
\hline Institution_6 & 0.043 & 0.043 & 0.142 & 0.188 & 0.188 \\
\hline Set of indicators & 0.1 & 0.1 & 0.15 & 0.1 & 0.05 \\
\hline Consensus value & 0.087 & 0.072 & 0.202 & 0.104 & 0.110 \\
\hline
\end{tabular}

Table 6. Transparency-indicator weighting. Budgeting and economic information disclosure block. Continuation

\begin{tabular}{|l|c|c|c|c|c|}
\hline & TR4.6 & TR4.7 & TR4.8 & TR4.9 & TR4.10 \\
\hline Institution_1 & 0.048 & 0.080 & 0.048 & 0.166 & 0.166 \\
\hline Institution_2 & 0.035 & 0.046 & 0.046 & 0.269 & 0.017 \\
\hline Institution_3 & 0.069 & 0.097 & 0.069 & 0.069 & 0.097 \\
\hline Institution_4 & 0.061 & 0.033 & 0.201 & 0.061 & 0.061 \\
\hline Institution_5 & 0.085 & 0.038 & 0.085 & 0.085 & 0.088 \\
\hline Institution_6 & 0.188 & 0.071 & 0.043 & 0.071 & 0.023 \\
\hline Set of indicators & 0.1 & 0.1 & 0.1 & 0.1 & 0.1 \\
\hline Consensus value & 0.066 & 0.064 & 0.110 & 0.107 & 0.078 \\
\hline
\end{tabular}


Both experts and public authorities agree that public availability of financial statements and the audit report (TR4.3) is the most important aspect, which is also consistent with the higher extent of compliance of this indicator (inexcusable compliance). However, despite the fact that public authorities consider this indicator to have the highest weight (weight CONGDE = 0.15 ), it would be more logical to revise this magnitude and increase the weight for this indicator, helping it resemble the weight given by the experts (consensus weight value $=0.202$ ). In short, this indicator should still be considered to be an inexcusable-compliance increasing its weighting by public authorities, in consonance with the opinion of the experts.

Finally, two of the indicators that are considered to be "merely relevant" in terms of representing transparency in the field of NPO's economic information differ in importance according to the experts and the public authorities. The reporting of the origin and applicaction of the funds received by NPOs (TR4.7) is overweighted by public authorities, the valuation of its importance being about half of that given by the experts (weight CONGDE $=0.1$; consensus weight value $=0.064$ ). In contrast, the indicator relative to the public availability of the socialy activities records (TR4.5) is given considerably greater importance by the experts, duplicating the value (weight CONGDE $=0.05$; consensus weight value $=0.11$ ).

In conclusion, there is evidence of a greater agreement between experts and public authorities on what is more important or less important in this block of indicators concerning the economic information of the NPOs. However, the magnitude of the importance proposed by CONGDE for the indicators TR4.3, TR4.5 and TR4.7 could be revised to make it more similar to the importance perceived by those experts who work day by day involved in the activity of the NPOs.

As a final comment on the results from all blocks of indicators, the detection of differences in the perceived importance of most of the indicators as indicative of transparency is in line with the diverse conclusions that can be extracted from the scant number of studies that have empirically measured transparency. In these studies, which partially explain concrete aspects of transparency in the accountability of NPOs, there is no a common agreement on which of the aspects are more important, talking about aspects so diverse as the importance of avoiding the inaccuracy of disclosed information (Burger \& Owens, 2010; Cabedo et al., 2018), the public availability of information in the websites (Gandía, 2011), or the need of informing on several aspects related to the use of perceived funds (Cabedo et al., 2018; Valencia et al., 2015). With the analysis that we have proposed, we have contributed by shedding light on all of these previous studies, by proposing an optimal weight for the importance of those and other aspects as indicative of the extent of transparency measurement.

\section{Robustness tests. The consistency ratio}

The fact that data was collected from questionnaires may generate inconsistency in the BWM technique because the participants might answer randomly. To solve this problem, the BWM establishes the analysis of the consistency ratio (see Eq. (2)), which is an indicator that measures the coherence of the weights given by the participants. In this sense, values that are closer to 0 indicate a better coherence.

We show the consistency ratio values in Table 7. Results are given to the institutions with the aim of detecting possible inconsistencies with any of their answers. 
Table 7. Consistency ratio

\begin{tabular}{|l|c|c|c|c|c|}
\hline & General aspects & TR1 & TR2 & TR3 & TR4 \\
\hline Institution_1 & 0.126 & 0.000 & 0.000 & 0.000 & 0.000 \\
\hline Institution_2 & 0.000 & 0.000 & 0.000 & 0.000 & 0.000 \\
\hline Institution_3 & 0.076 & 0.000 & 0.000 & 0.000 & 0.000 \\
\hline Institution_4 & 0.000 & 0.000 & 0.000 & 0.000 & 0.000 \\
\hline Institution_5 & 0.091 & 0.000 & 0.000 & 0.000 & 0.000 \\
\hline Institution_6 & 0.028 & 0.000 & 0.000 & 0.000 & 0.000 \\
\hline
\end{tabular}

In Liang et al. (2019) was carried out a study in order to show acceptable thresholds of consistency in BWM depending on the scale used by the experts to express their preferences and the number of criteria used in the MCGDM problem. According to (Liang et al., 2019), the acceptable values of consistency taking into account the scale (1-5) and number of criteria used in this contribution (4, 5, 7 and 10) are between 0.1994 and 0.2960 . Therefore, the consistency ratio values obtained from experts' preferences confirm the consistency of all of the weights that have been estimated with the BWM.

In conclusion, the analysis carried out to compare the different experts' opinions regarding the importance given to the different areas of transparency is consistent. Thus, the suggestions we have made to public authorities could be considered to be rigorous.

\section{Conclusions and limitations}

Transparency has become a factor of high strategic value for NPOs to be able to ensure their own survival. However, there is no legal regulation that requires NPOs to justify the extent of the transparency in their performance management. In response to this situation, in order to build credibility among their stakeholders, these entities have voluntarily opted for selfregulation: some sets of indicators on the extent of transparency that are scarcely validated empirically.

In this study we show that the formalization of a process for indicators weighting may contribute to literature by improving the measurement of transparency in the Non-profit Sector. In line with recent studies that propose the use of multi-criteria decision-making optimization techniques (see, for example Moreno-Albarracín et al., 2020), but focusing specifically on transparency, we aim to improve NPO accountability by, empirically validating proposals made by public authorities. Our results show that the block of indicators that are considered to be the most important when measuring transparency in NPOs are those from TR4 block "Structure and composition of their budgeting process and activities, and their economic and financial structure" (consensus value $=0.517$ ), and those from TR2 block "Definition of the mission, vision, and values" (consensus value $=0.252$ ).

Interestingly, we have found significant differences between the weights of the indicators that are obtained from the experts and those that are proposed by the CONGDE, given that the indicators that were proposed by the CONGDE, as previously stated, are not based on any empirical validation according to the experts. Analysing such differences by blocks, 
the greater divergence comes from indicators TR1.1 (valuation of experts is 0.125 lower), TR2.3 (0.065 lower), TR3.1 (0.123 lower), and TR4.5 (0.06 greater). The indicators with the highest value in each group are "Statutes and other specific rules" (TR1.4; consensus value = 0.405); "Definition of the mission of the entity" (TR2.1; consensus value $=0.296$ ); "List of the networks or federations to which the entity belong" (TR3.3; consensus value $=0.222$ ); and "Annual financial statements of the entity" (TR4.3; consensus value $=0.202$ ).

The analysis of the results has allowed us to build a set of indicators that is appropriately validated by the opinion of NPO accountability experts, giving a single, optimal weight to every indicator and block of indicators. As such, our study contributes not only to previous literature on transparency of accountability for NPOs by proposing a rigorously empirically validated set of indicators, but it also contributes to regulators and public authorities, serving as a guide for future adaptations of the sets of indicators, as well as for those in charge of an NPO's accountability.

Concerning limitations, whilst this method could be applicable to any NPO context, specific conclusions are limited to a Spanish setting. Furthermore, we are aware that the sample is reduced. In this sense, although the experts come from the main NPOs in Spain and that these entities cover very diverse social needs, a potential limitation may be the bias in the evaluation because of the reduced number of experts. It would be necessary to extend the sample with other experts to check if the results are comparable in other countries, thereby reducing the aforementioned evaluation bias. Additionally, as a future line of research, it would be interesting to undertake a comparative study of transparency measurements in NPOs with indicators in an international setting and observing potential differences between countries.

\section{Funding}

This research was funded by the Instituto de Estudios Giennenses (Diputación de Jaén, Spain) and the Spanish Ministry of Economy and Competitiveness through the Spanish National Research Projects PGC2018-099402-B-I00.

\section{Author contributions}

Conceptualization, ALM.-A and CO-R; methodology, LM and AL; software, LM and AL; formal analysis, AL-G; investigation, ALM-A; resources, LM and AL; data, ALM-A, AL-G and AL.; questionnaire, ALM-A, AL-G and AL; writing - original draft preparation, ALM-A, CO-R., AL-G, LM and AL; writing, review and editing, ALM-A, AL-G and CO-R; supervision, ALM-A and LM.

\section{Disclosure statement}

Authors declare not have any competing financial, professional, or personal interests from other parties. 


\section{References}

Anwar, M., Khattak, M. S., Popp, J., Meyer, D. F., \& Máté, D. (2020). The nexus of government incentives and sustainable development goals: is the management of resources the solution to non-profit organisations? Technological and Economic Development of Economy, 26(6), 1284-1310. https://doi.org/10.3846/tede.2020.13404

Austin, J. E. (2000). Strategic collaboration between nonprofits and businesses. Nonprofit and Voluntary Sector Quarterly, 29(1_suppl), 69-97. https://doi.org/10.1177/0899764000291S004

Ben-Arieh, D., \& Easton, T. (2007). Multi-criteria group consensus under linear cost opinion elasticity. Decision Support Systems, 43(3), 713-721. https://doi.org/10.1016/j.dss.2006.11.009

Benjamin, L. M. (2008). Account space: How accountability requirements shape nonprofit practice. Nonprofit and Voluntary Sector Quarterly, 37(2), 201-223. https://doi.org/10.1177/0899764007301288

Burger, R., \& Owens, T. (2010). Promoting transparency in the NGO sector: Examining the availability and reliability of self-reported data. World Development, 38, 1263-1277. https://doi.org/10.1016/j.worlddev.2009.12.018

Butler, C. L., \& Rothstein, A. (2007). On conflict and consensus: A handbook on formal consensus decisionmaking. Mountain. Mountain View, CA. Creative Commons.

Cabedo, J. D., Fuertes-Fuertes, I., Maset-LLaudes, A., \& Tirado-Beltrán, J. M. (2018). Improving and measuring transparency in NGOs: A disclosure index for activities and projects. Nonprofit Management and Leadership, 28(3), 329-348. https://doi.org/10.1002/nml.21298

Celik, E., \& Gumus, A. T. (2018). An assessment approach for non-governmental organizations in humanitarian relief logistics and an application in Turkey. Technological and Economic Development of Economy, 24(1), 1-26. https://doi.org/10.3846/20294913.2015.1056277

Cestari, J. M. A. P., de Lima, E. P., Deschamps, F., Van Aken, E. M., Treinta, F., \& Moura, L. F. (2018). A case study extension methodology for performance measurement diagnosis in nonprofit organizations. International Journal of Production Economics, 203, 225-238.

https://doi.org/10.1016/j.ijpe.2018.06.018

CONGDE. (2019). Herramienta de transparencia y buen gobierno. Plataforma de ONG de Acción Social $y$ Coordinadora de ONGD-España.

Džunić, M., Stanković, J., \& Janković-Milić, V. (2018). Multi-criteria approach in evaluating contribution of social entrepreneurship to the employment of socially-excluded groups. Technological and Economic Development of Economy, 24(5), 1885-1908. https://doi.org/10.3846/20294913.2017.1347906

Estrella, F. J., Espinilla, M., Herrera, F., \& Martínez, L. (2014). FLINTSTONES: A fuzzy linguistic decision tools enhancement suite based on the 2-tuple linguistic model and extensions. Information Sciences, 280, 152-170. https://doi.org/10.1016/j.ins.2014.04.049

Franco, C. M. M., \& Raja, I. G. (2014). Medida de la eficiencia en entidades no lucrativas: un estudio empírico para fundaciones asistenciales. Revista de Contabilidad-Spanish Accounting Review, 17(1), 47-57. https://doi.org/10.1016/j.rcsar.2013.08.005

Gandía, J. L. (2011). Internet disclosure by nonprofit organizations: Empirical evidence of nongovernmental organizations for development in Spain. Nonprofit and Voluntary Sector Quarterly, 40(1), 57-78. https://doi.org/10.1177/0899764009343782

Greenlee, J., Fischer, M., Gordon, T., \& Keating, E. (2007). An investigation of fraud in nonprofit organizations: Occurrences and deterrents. Nonprofit and Voluntary Sector Quarterly, 36(4), 676-694. https://doi.org/10.1177/0899764007300407

Hale, K. (2013). Understanding nonprofit transparency: the limit of formal regulation in the American nonprofit sector. International Review of Public Administration, 18(3), 31-49.

https://doi.org/10.1080/12294659.2013.10805262 
Hofmann, M. A., \& McSwain, D. (2013). Financial disclosure management in the nonprofit sector: A framework for past and future research. Journal of Accounting Literature, 32(1), 61-87. https://doi.org/10.1016/j.acclit.2013.10.003

Keating, E. K., \& Frumkin, P. (2003). Reengineering nonprofit financial accountability: Toward a more reliable foundation for regulation. Public Administration Review, 63(1), 3-15. https://doi.org/10.1111/1540-6210.00260

Kim, M. (2017). The relationship of nonprofits' financial health to program outcomes: Empirical evidence from nonprofit arts organizations. Nonprofit and Voluntary Sector Quarterly, 46(3), 525-548. https://doi.org/10.1177/0899764016662914

Labella, Á., Liu, Y., Rodríguez, R. M., \& Martínez, L. (2018). Analyzing the performance of classical consensus models in large scale group decision making: A comparative study. Applied Soft Computing Journal, 67, 677-690. https://doi.org/10.1016/j.asoc.2017.05.045

Liang, F., Brunelli, M., \& Rezaei, J. (2019). Consistency issues in the best worst method: Measurements and thresholds. Omega, 102175. https://doi.org/10.1016/j.omega.2019.102175

Manville, G., \& Greatbanks, R. (2016). Third sector performance: Management and finance in not-forprofit and social enterprises. Routledge. https://doi.org/10.4324/9781315551098

Moreno-Albarracín, A. L., Licerán-Gutierrez, A., Ortega-Rodríguez, C., Labella, Á., \& Rodríguez, R. M. (2020). Measuring what is not seen - Transparency and good governance nonprofit indicators to overcome the limitations of accounting models. Sustainability, 12(18), 7275.

https://doi.org/10.3390/su12187275

Moreno, P. D. C., Alcaide, T. C. H., \& San Juan, A. I. S. (2016). La transparencia organizativa y económica en la Web de las fundaciones: un estudio empírico para España. REVESCO: Revista de Estudios Cooperativos, 121, 62-88. https://doi.org/10.5209/rev_REVE.2016.v121.49701

Ortega-Rodríguez, C., Licerán-Gutiérrez, A., \& Moreno-Albarracín, A. L. (2020). Transparency as A key element in accountability in non-profit organizations: A systematic literature review. Sustainability, 12(14), 5834. https://doi.org/10.3390/su12145834

Rezaei, J. (2015). Best-worst multi-criteria decision-making method. Omega, 53, 49-57. https://doi.org/10.1016/j.omega.2014.11.009

Righi, A., \& Andreoni, V. (2014). Towards a comparable and harmonised set of performance indicators for Third Sector organisations: The Italian experience. International Journal of Productivity and Performance Management, 63(6), 766-778. https://doi.org/10.1108/IJPPM-09-2013-0152

Rodríguez, R. M., Labella, Á., De Tré, G., \& Martínez, L. (2018). A large scale consensus reaching process managing group hesitation. Knowledge-Based Systems, 159, 86-97.

https://doi.org/10.1016/j.knosys.2018.06.009

Saaty, T. L. (1989). Group decision making and the AHP. In B. L. Golden, E. A. Wasil, \& P. T. Harker (Eds.), The analytic hierarchy process (pp. 59-67). Springer. https://doi.org/10.1007/978-3-642-50244-6_4

Saint, S., \& Lawson, J. R. (1994). Rules for reaching consensus: a modern approach to decision making. Wiley.

Sanzo-Pérez, M. J., Rey-Garcia, M., \& Álvarez-González, L. I. (2017). The drivers of voluntary transparency in nonprofits: Professionalization and partnerships with firms as determinants. VOLUNTAS: International Journal of Voluntary and Nonprofit Organizations, 28(4), 1595-1621. https://doi.org/10.1007/s11266-017-9882-9

Saxton, G. D., \& Guo, C. (2011). Accountability online: Understanding the web-based accountability practices of nonprofit organizations. Nonprofit and Voluntary Sector Quarterly, 40(2), 270-295. https://doi.org/10.1177/0899764009341086 
Schatteman, A. (2013). Nonprofit accountability: To whom and for what? An introduction to the special issue. International Review of Public Administration, 18(3), 1-6. https://doi.org/10.1080/12294659.2013.10805260

Speckbacher, G. (2008). Nonprofit versus corporate governance: An economic approach. Nonprofit Management \& Leadership, 18(3), 295-320. https://doi.org/10.1002/nml.187

Tacon, R., Walters, G., \& Cornforth, C. (2017). Accountability in nonprofit governance: A process-based study. Nonprofit and Voluntary Sector Quarterly, 46(4), 685-704. https://doi.org/10.1177/0899764017691637

Tremblay-Boire, J., \& Prakash, A. (2015). Accountability.org: Online disclosures by US nonprofits. VOLUNTAS: International Journal of Voluntary and Nonprofit Organizations, 26(2), 693-719. https://doi.org/10.1007/s11266-014-9452-3

Valencia, L. A. R., Queiruga, D., \& González-Benito, J. (2015). Relationship between transparency and efficiency in the allocation of funds in nongovernmental development organizations. VOLUNTAS: International Journal of Voluntary and Nonprofit Organizations, 26(6), 2517-2535. https://doi.org/10.1007/s11266-014-9527-1

Valentinov, V., \& Vaceková, G. (2015). Sustainability of rural nonprofit organizations: Czech Republic and beyond. Sustainability, 7(8), 9890-9906. https://doi.org/10.3390/su7089890

Willems, J., Boenigk, S., \& Jegers, M. (2014). Seven trade-offs in measuring nonprofit performance and effectiveness. VOLUNTAS: International Journal of Voluntary and Nonprofit Organizations, 25(6), 1648-1670. https://doi.org/10.1007/s11266-014-9446-1 